\title{
Programas de enriquecimento escolar para alunos com altas habilidades ou superdotação: análise de publicações brasileiras
}

\author{
Lurian Dionizio Mendonça* \\ Gislaine Ferreira Menino Mencia ${ }^{* *}$ \\ Vera Lúcia Messias Fialho Capellini***
}

\section{Resumo}

O Modelo de Enriquecimento Escolar proposto por Joseph Renzulli tem como objetivo tornar a escola um espaço no qual os talentos sejam identificados e desenvolvidos. Esse modelo tem como propósito expor o aluno com altas habilidades ou superdotação a vários tópicos, áreas de interesse e campos de estudo para aplicação de conhecimentos e conteúdos avançados, treinamento de habilidades e uso de metodologias para o desenvolvimento e crescimento no campo que lhe beneficia, tornando-o capaz de alcançar altos níveis de desempenho. Assim, o presente estudo teve como objetivo analisar a produção nacional de artigos científicos, no período de 2000 a 2012, referentes aos programas de enriquecimento escolar, com o propósito de descrever como os alunos com altas habilidades ou superdotação são atendidos nesses programas. Dos estudos analisados, nenhum teve como propósito expor como os alunos foram atendidos sistematicamente durante a sua participação no programa de enriquecimento, mas no geral, tinham como objetivo oportunizar aos alunos com indicadores de altas habilidades ou superdotação atividades enriquecedoras que possibilitassem o desenvolvimento do seu potencial e que atendessem suas necessidades especiais. No entanto, apesar das dificuldades encontradas na implementação e efetivação dos programas, observa-se que gradualmente estáo sendo colocados em prática e se adaptando às teorias propostas. Portanto, considera-se de suma importância que haja novos estudos sobre o enriquecimento escolar, de maneira a tornar a prática cada vez mais efetiva.

Palavras-chave: Programas de enriquecimento escolar; Altas habilidades ou superdotação; Revisão de publicaçóes.

\footnotetext{
* Mestre em Psicologia pela Universidade Estadual Paulista Júlio de Mesquita Filho. Bauru, São Paulo, Brasiil.

** Mestranda em Psicologia do Desenvolvimento e Aprendizagem, Universidade Estadual Paulista, Júlio de Mesquita Filho. Bauru, São Paulo, Brasil.

*** Professora doutora da Universidade Estadual Paulista Júlio de Mesquita Frilho. Bauru, São Paulo, Brasil.
} 


\title{
School enrichment programs for students with high abilities or giftedness: analysis of Brazilian publications
}

\begin{abstract}
The school enrichment proposed by Joseph Renzulli aims to make school a place where talents are identified and developed. This model aims to expose students with high ability or giftedness to various topics, areas of interest and fields of study for application of knowledge and advanced content, skills training and the use of methodologies for development and growth in the field that benefits you, making it able to achieve high levels of performance. Thus, this study aimed to analyze the domestic production of scientific papers, from 2000 to 2012, relating to school enrichment programs, in order to describe how students with high ability or giftedness are served in these programs. Of the studies analyzed, none aimed to expose how the students were systematically met while participating in the enrichment program, but overall, aimed to create opportunities for students with indicators of high ability or giftedness, enriching activities to promote the development of their potential and that met their special needs. However, despite the difficulties encountered in the implementation and execution of the programs, it is observed that gradually are being put into practice and adapting to the theories proposed. Therefore, it is considered of paramount importance that there is further study on academic enrichment, in order to make increasingly effective practice.
\end{abstract}

Keywords: School enrichment programs; High ability or giftedness; Review of publications.

\section{Introdução}

Os alunos com altas habilidades ou superdotação são caracterizados pelo alto desempenho e/ou elevada potencialidade em qualquer dos seguintes aspectos, isolados ou combinados: capacidade intelectual geral, aptidão acadêmica específica, pensamento criativo e/ou produtivo, capacidade de liderança, talento especial para as artes e capacidade psicomotora (VIRGOLIM, 2007).

Os sistemas educacionais, de acordo com a Educação Inclusiva, têm como finalidade prover os espaços educativos, de modo que todos os alunos pudessem se beneficiar de serviços apropriados, considerando-se, ainda, o aluno com altas habilidades ou superdotação como mais uma manifestação dentro do contínuo das diferenças humanas. Assim, o sistema educativo deverá organizar-se para promover um conjunto de respostas apropriadas às suas capacidades, interesses e ritmos de aprendizagem, uma vez que, a educação ainda privilegia um ensino voltado para a memorização e reprodução de conhecimento, negligenciando o pensamento crítico, flexível e original. Uma escola inclusiva, também para estes alunos, deve atender ao seu desenvolvimento cognitivo, mas também à sua realidade social e emocional, ou 
seja, às suas necessidades individuais específicas, no sentido da promoção da excelência e da prevenção de possíveis dificuldades.

$\mathrm{Na}$ Constituição Federal de 1988, no seu artigo 208, inciso V, é estabelecido que o dever do Estado com a educação será efetivado mediante a garantia de: acesso aos níveis mais elevados do ensino; de pesquisa e de criação artística, segundo a capacidade de cada um, podendo, assim, ser interpretado como aplicável a todas as pessoas com altas habilidades ou superdotação (FREITAS, 2006).

Apesar do aumento no interesse pela temática da superdotação, segundo Antipoff (2010), ainda há uma enorme distorção da identidade das pessoas com altas habilidades ou superdotação. Rech e Freitas (2005) afirmam que isso acaba dificultando a real "visualização". Isso ocorre porque, para uma parcela da sociedade, esses indivíduos não passam de mitos, o que dificulta sua identificação e, consequentemente, seu encaminhamento para um atendimento especializado, que, por vezes, é questionado e visto como desnecessário.

Contudo, o enriquecimento escolar, que foi proposto pelo educador norte -americano Joseph Renzulli, é uma das alternativas mais conhecidas para o atendimento educacional de alunos com altas habilidades ou superdotação, que tem por objetivo tornar a escola um lugar onde os alunos talentosos possam ser identificados e suas habilidades desenvolvidas (RENZULLI; REIS, 1997).

O enriquecimento escolar tem como propósito expor o aluno com altas habilidades ou superdotação a vários tópicos, áreas de interesse e campos de estudo para aplicação de conhecimentos e conteúdos avançados, treinamento de habilidades e uso de metodologias para o desenvolvimento e crescimento no campo que lhe beneficia, tornando-o capaz de alcançar altos níveis de desempenho (RENZULLI; REIS, 1997).

No entanto, antes de serem encaminhados aos programas de enriquecimento curricular, os alunos com altas habilidades ou superdotação precisam ser identificados, mas devido à falta de instrumentos que avaliem as habilidades que não são, exclusivamente, a acadêmica, como por exemplo, as habilidades musicais ou de liderança, e a falta de conhecimento por parte dos profissionais, juntamente com as visōes distorcidas sobre essa população, as pessoas com altas habilidades ou superdotação ainda não são identificadas e, quando são, muitas vezes, são diagnosticadas erroneamente. Weeb e Latimer (1993) apontam que vários comportamentos diagnósticos para Transtorno de Déficit de Atenção e Hiperatividade (TDAH) podem ser encontrados em alunos com altas habilidades ou superdotaçáo, o que aumenta potencialmente o erro na identificação. No processo de identificação e caracterização dos indivíduos com altas habilidades ou superdotação deve ser realizada uma variedade de técnicas e instrumentos, pois o potencial desses indivíduos pode ser expresso em diversas maneiras, no entanto, infelizmente, ainda hoje existem programas que, em seu processo de identificação, utilizam apenas testes de inteligência. Essa prática traz como consequência a subnomeaçáo de indivíduos superdotados. 
Várias são as alternativas de atendimento oferecidas aos alunos com altas habilidades ou superdotação e cada uma delas atende a diferentes necessidades. Todavia, há que se lembrar de que não existe um modelo ideal, mas podemos considerar que um método adequado é um conjunto de combinaçóes entre alternativas de atendimentos possíveis (CUPERTINO, 2008). Para Landau (2002, p. 35) "um bom sistema educacional deve adaptar-se às necessidades da criança, estimulando sua potencialidade e fortalecendo suas fraquezas".

As atividades enriquecedoras caracterizam-se pela diversidade de ofertas ao aluno, uma vez que buscam trabalhar as áreas do conhecimento de seu interesse, pautando-se na realização de atividades de cunho pedagógico e com estratégias criativas e adaptadas ao currículo que venham a ser desenvolvidas (NOVAES, 2002).

Os principais métodos utilizados são: o agrupamento, a aceleração e o enriquecimento. O agrupamento (segregação) é o atendimento de alunos em escolas ou classes especiais, ou sob a forma de pequenos grupos na sala de aula regular de forma diferenciada dos demais, consistindo em escolher e separar os estudantes por nível de habilidade ou desempenho (FLEITH, 2007a). Já a aceleração, permite que o aluno avance etapas da formação regular, o que implica decidir que a competência, e não a idade, será critério determinante para que o indivíduo obtenha acesso a um currículo e experiências acadêmicas mais adiantadas (VIRGOLIM, 2007). E o enriquecimento oferece ao aluno experiências de aprendizagem diversas daquelas que o currículo regular apresenta, podendo ser feito pelo acréscimo de conteúdos mais abrangentes e/ ou mais profundos, e/ou pela solicitação de projetos originais (CUPERTINO, 2008).

No entanto, para que o enriquecimento escolar seja implementado, é necessário que haja um consenso entre a equipe de direção, os professores, bem como o envolvimento e comprometimento de toda a comunidade escolar na discussão e no planejamento das atividades, além do estabelecimento de metas, prioridades e objetivos a serem alcançados.

Esse modelo proposto por Renzulli (1998) é bastante flexível, existindo três tipos de atividades de enriquecimento: atividades do tipo I, atividades do tipo II e atividades do tipo III. As atividades do tipo I são experiências e atividades exploratórias, com a função de colocar o aluno em contato com as áreas de conhecimento que, geralmente, não são contempladas no currículo regular. Nas atividades de enriquecimento do tipo II, tem-se como objetivo desenvolver nos alunos habilidades de "como fazer", de modo a instrumentá-los a investigar problemas usando metodologias adequadas à área de conhecimento e de interesse. Já as atividades do tipo III visam a investigação de problemas reais, através da produção de um conhecimento novo, da solução de problemas ou da apresentação de um produto, serviço ou performance, cujas atividades desenvolvem habilidades de planejamento, gerenciamento do tempo, avaliação e habilidades sociais de interação com especialistas, professores e colegas. Assim,

atender a diversidade na superdotação, sem dúvida, é um grande desafio. Ainda mais se considerarmos a grande amplitude de expressóes e habilidades existentes, assim como a combinação única de traços de personalidade e história de vida que evidenciam a 
particularidade de cada um dos indivíduos com altas habilidades. Não existe traço único de personalidade ou característica estável que represente pessoas com superdotaçáo ou altas habilidades. (FLEITH; ALENCAR, 2007, p. 173).

De acordo com Renzulli e Reis (1997), os programas de enriquecimento para alunos superdotados e talentosos têm sido os verdadeiros laboratórios de escolas do mundo, porque eles têm apresentado oportunidade ideal para testar novas ideias e experiências com as possíveis soluçóes para antigos problemas educacionais.

Dessa forma, "os alunos com altas habilidades/superdotação necessitam de serviços educacionais diferenciados que possam promover o seu desenvolvimento acadêmico, artístico, psicomotor e social, o que inclui métodos de ensino adaptados às suas necessidades especiais" (VIRGOLIM, 2007, p. 66).

Contudo, o enriquecimento escolar também pode ser ofertado pelo professor, dentro da sala de aula comum, seja com atividades no contraturno, como uma tarefa de casa mais elaborada que a oferecida aos demais alunos da sala de aula ou por meio de outras atividades, como por exemplo, em matemática, ao usar folhetos de supermercado para trabalhar as quatro operaçôes, o professor pode solicitar aos alunos com altas habilidades ou superdotação para que aprofundem as questóes, pensando como ficaria a conta se houvesse uma promoção ou quais produtos um cliente teria de deixar de comprar se tivesse menos dinheiro do que o valor final.

Outra situação que o professor também pode promover é a integração desses alunos, ao pedir que auxiliem aos colegas que estão com alguma dificuldade, e, além disso, a sala de aula pode ter vários livros, revistas e jornais para que todos os alunos, nâo somente aqueles com altas habilidades ou superdotação, possam ler nos intervalos ou quando acabarem as atividades antes que os demais, impedindo, assim, que fiquem ociosos e entediados.

Logo, o enriquecimento curricular dos alunos com altas habilidades ou superdotação pode ser feito dentro da sala de aula e sem a necessidade de outros recursos, que muitas vezes a escola pode náo ter, como laboratórios de informática, de ciências, etc. Outra prática que pode ser realizada para solucionar tais dificuldades é a realização de parcerias com outras instituições, como as universidades, por exemplo.

Assim, o presente estudo teve como objetivo analisar a produçáa nacional de artigos científicos, no período de 2000 a 2012, referentes aos programas de enriquecimento escolar, com o propósito de descrever como os alunos com altas habilidades ou superdotaçáo são atendidos nesses programas.

\section{Método}

Para atingir o objetivo proposto, foi realizado um levantamento dos artigos científicos brasileiros sobre os programas de enriquecimento escolar, por meio de busca eletrônica indexada no Portal de Periódicos da CAPES (Coordenação de Aperfeiçoamento de Pessoal de Nível Superior), biblioteca virtual que reúne e disponibiliza artigos de diversos periódicos nacionais e internacionais. 
As buscas foram realizadas no período de 2000 a 2012, selecionando-se as publicações nacionais, a partir dos seguintes descritores: programa de enriquecimento educacional/escolar; sala de recursos; atendimento educacional; altas habilidades; superdotação, sendo que as palavras "altas habilidades" e "superdotação" foram pesquisadas juntamente com os outros descritores.

O material de análise foi selecionado a partir da leitura prévia dos resumos encontrados, sendo incluídos somente os trabalhos que descreviam sobre o atendimento educacional oferecido aos alunos com altas habilidades ou superdotação. Após a leitura integral de cada texto, os trabalhos foram separados por ano de publicação e periódico.

A análise dos dados se deu a partir das descrições quantitativas das produçóes e qualitativamente por meio da interpretação dos dados encontrados, tomando como base a literatura referente à área pesquisada, uma vez que o método qualitativo busca realizar um exame intensivo dos dados, tanto em amplitude quanto em profundidade (MARTINS, 2004), sendo que a preocupação com o processo é muito maior do que com o produto (BODGAN; BIKLEN, 1982 apud LÜDKE; ANDRÉ, 1986).

\section{Resultados e discussões}

$\mathrm{Na}$ base de dados da CAPES, apareceu um total de 17 artigos publicados, contudo, como a busca foi realizada com palavras combinadas, 8 artigos foram descartados, pois se repetiam, ou seja, se referiam a mesma pesquisa e, durante a leitura dos resumos, mais 2 foram descartados, pois náo se referiam aos programas de atendimento, um descrevia os serviços educacionais oferecidos a populaçáo da Educaçáo Especial, de um modo geral, e o outro tinha como objetivo comparar as características de estudantes com transtorno obsessivo-compulsivo e altas habilidades ou superdotação e discutir as ofertas de atividades escolares oferecidas ao público alvo. Sendo assim, foram utilizados para a análise 7 artigos, conforme descritos na Tabela 1.

\begin{tabular}{l|l}
\hline $\begin{array}{l}\text { No } \\
1\end{array}$ & $\begin{array}{l}\text { ARTIGOS } \\
\text { Avaliação das práticas educacionais de um programa de atendimento a alunos } \\
\text { superdodos e talentosos. } \\
\text { CEDET - um programa de sucesso na educação de dotados e talentosos. } \\
\text { Entrevista com a Profa } . \text { Dra. Zenita Cunha Guenther. }\end{array}$ \\
3 & Centros comunitários para desenvolvimento de talento - O CEDET. \\
4 & Efeitos de um Programa de Enriquecimento: descrição e resultados parciais.
\end{tabular}

Tabela 1: Artigos sobre Programas de Enriquecimento Escolar. 
$5 \quad$ O atendimento em salas de recursos para alunos com altas habilidades/ superdotação: o caso do Paraná.

6

Olhar e oportunidade aos alunos com potencial superior: uma experiência aberta ao diálogo. pedagógicas realizadas com alunos com características de altas habilidades.

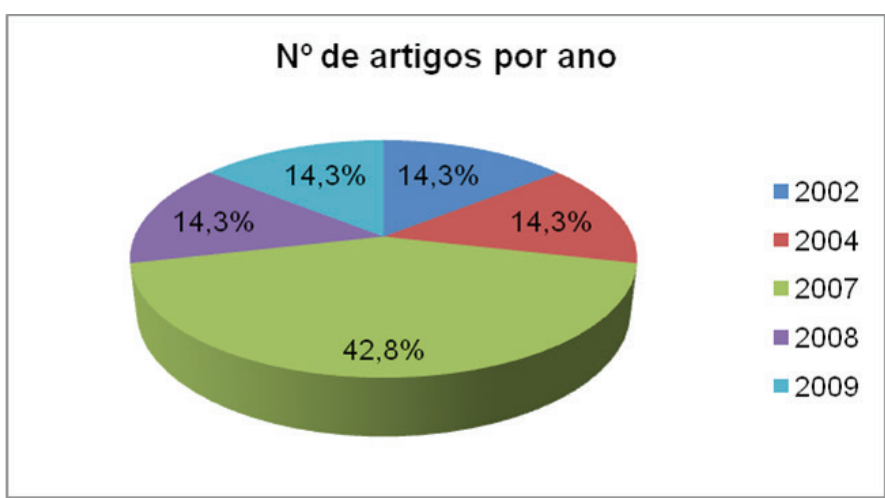

Gráfico 1: Número de artigos por ano.

Entre os artigos encontrados, 14,3\% (1/7) foram publicados no ano de 2002, 2004, 2008 e 2009. Somente no ano de 2007 foram observadas mais publicações, 42,8\% (3/7) como mostra o Gráfico 1. Desses trabalhos, 28,5\% (2/7) foram publicados na Revista de Educação Especial da Universidade Federal de Santa Maria/RS e os demais estão distribuídos em diferentes periódicos: Ensaio: Avaliação e Políticas Públicas em Educação, da Fundação CESGRANRIO/RJ; Psicologia em Pesquisa, da Universidade Federal de Juiz de Fora/MG; Psicologia Escolar e Educacional, da Associação Brasileira de Psicologia Escolar e Educacional (ABRAPEE); Revista Brasileira de Educação Especial, da Associação Brasileira de Pesquisadores em Educação Especial (ABPEE) e Revista Contrapontos, do Programa de Pós-Graduação em Educação da Univali/SC.

Dos trabalhos analisados, 28,5\% (2/7) foram realizados no Centro para Desenvolvimento do Potencial e Talento (CEDET), localizado em Lavras/MG, 28,5\% (2/7) foram desenvolvidos no Programa de Incentivo ao Talento (PIT), da Universidade Federal de Santa Maria/RS, 14,3\% (1/7) no Programa Experimental de Desenvolvimento Instrumental (PEDI), da Universidade Estadual do Rio de Janeiro/RJ, 14,3\% (1/7) no Programa de Atendimento a Alunos Portadores de Altas Habilidades e Talentosos (PAAPAHT), da Secretaria de Educação do Distrito Federal e 14,3\% (1/7) dos estudos foram desenvolvidos nas Salas de Recursos (SR) do estado do Paraná, como demonstrado no Gráfico 2. 


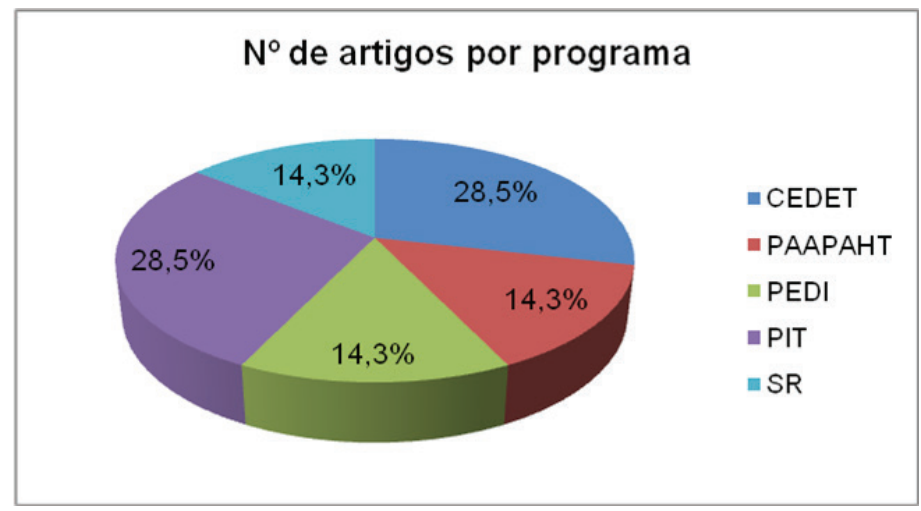

Gráfico 2: Número de artigos por programa.

Dentre os estudos investigados, o de autoria de Mettrau e Gonçalves (2002), intitulado "Efeitos de um programa de enriquecimento: descrição e resultados parciais", buscou verificar os efeitos causados nos participantes que frequentaram o PEDI entre os anos de 1983 e 1986, por meio de entrevistas semiestruturadas. O referido programa tinha como propósito oportunizar aos alunos, com indicadores de altas habilidades ou superdotação, atividades enriquecedoras que possibilitassem o desenvolvimento do seu potencial e de suas necessidades especiais. O PEDI realizava reuniôes semanais com os alunos, mensais com os pais e reuniôes quinzenais para o planejamento das atividades com a equipe técnica.

Como o estudo ainda estava em fase de coleta de dados, os resultados disponibilizados, na publicação, foram parciais, nos quais os autores puderam organizar algumas consideraçôes em relaçáo aos participantes, como: o prazer no reencontro; as lembranças das atividades desenvolvidas e utilização de estratégias e ferramentas aprendidas durante o programa; demonstração de interesse no estudo da área de altas habilidades (considerado pelos autores como um desdobramento inesperado); o interesse e/ou atuação em mais de uma área, como música e medicina; demonstração de preocupação com a coletividade, com as questóes éticas e humanitárias; e, por fim, os participantes deram como sugestão manter contato após o término do programa.

Assim, pode ser observado que este estudo não teve como propósito descrever como os alunos foram atendidos durante a participaçáo no programa, e, ainda, fez uma descrição superficial sobre as contribuiçóes da participação no programa de enriquecimento educacional na vida acadêmica e profissional desses alunos, sendo que esse estudo buscou resgatar os alunos dez anos após sua participação no programa.

No artigo "Avaliação das práticas educacionais de um programa de atendimento a alunos superdotados e talentosos", as autoras Maia-Pinto e Fleith (2004) buscaram avaliar um programa de atendimento ao superdotado e talentoso no que se refere às estratégias empregadas, verificando a extensão em que elas se diferenciam das implementadas em sala de aula regular e se atendem, de fato, as necessidades dos alunos que frequentam o programa. Delineado como um estudo experimental de abordagem quali-quantitativa, participaram como sujeitos 77 alunos que frequen- 
tavam o programa, onze professores do programa, seis professores de sala regular e seis mães de alunos do programa. Para a coleta de dados, foram utilizados o Teste do Pensamento Criativo - Produção de Desenhos (TCT-DP), visando avaliar o nível de criatividade dos indivíduos e Questionários de Atividades de Classe (CAQ), que avaliam o clima instrucional de sala.

Nos resultados, verificaram possíveis diferenças entre alunos com habilidades acadêmicas e alunos talentosos com relação ao rendimento acadêmico, pois os alunos com habilidades acadêmicas obtiveram um melhor rendimento acadêmico quando comparados aos alunos talentosos. A percepção dos alunos acerca das atividades e estratégias empregadas no programa é positiva, no sentido de esclarecer pontos sobre a capacidade de julgamento de alunos jovens sobre seus professores. As mães, apesar de avaliarem satisfatoriamente o programa, tinham poucas informaçóes sobre seus objetivos e as atividades desenvolvidas.

Desta forma, os resultados demonstram que os professores têm um conceito relativamente bem formado a respeito de superdotaçáo, mas que possuem um conhecimento limitado em relação ao modelo adotado (Modelo de Enriquecimento Escolar de Renzulli, 1986). Conclui-se, portanto, que os treinamentos e palestras nos últimos anos, não estão atendendo as dúvidas dos professores.

O trabalho "CEDET - um programa de sucesso na educação de dotados e talentosos", de Pereira e Gonçalves (2007), descreve uma entrevista realizada com a pesquisadora Zenita C. Guenther sobre a educação de um modo geral e da educação especial, e há também uma descrição do CEDET, como funciona, os objetivos do programa e como os participantes são selecionados.

Já o artigo "Centros comunitários para o desenvolvimento de talentos - O CEDET", de Guenther (2007), descreve como é desenvolvido o programa do CEDET, que busca integrar ao sistema escolar um programa para o desenvolvimento de superdotados e talentosos. A metodologia de identificação caracteriza-se pela busca ordenada dos alunos dotados na populaçáo escolar, sem esperar a indicação dos mesmos.

A coordenação pedagógica fundamenta-se em um referencial teórico com base no pensamento humanista, considerando as dimensóes básicas à formação da personalidade como o autoconceito, o conceito do outro e a visão de mundo.

Suas açôes envolvem a família, a comunidade e a escola no processo educativo. O processo de estimulação é dirigido por um Plano Individual de trabalho feito pelo aluno junto com o seu orientador, no intuito de alcançar dois objetivos: desenvolver a habilidade natural e o talento sinalizado e aprimorar aspectos da formação pessoal.

$\mathrm{O}$ estudo intitulado "O atendimento educacional realizado em salas de recursos para alunos com altas habilidades/superdotação: o caso do Paraná", de Mori e Brandão (2009), tem como característica a suplementação ou enriquecimento dos conteúdos escolares do currículo formal, bem como uma metodologia diferenciada, com recursos que atendam as necessidades peculiares dos alunos com altas habili- 
dades ou superdotação, tornando-se uma escola inclusiva e democrática para todos. Neste estudo, as escolas dispunham de dez salas de recursos e três Núcleos de Atividades de Altas Habilidades ou Superdotação (NAAH), nas quais são atendidos 220 alunos com altas habilidades ou superdotação, em que 74 frequentavam da $1^{\text {a à }} 4^{\mathrm{a}}$ série e 146 da $5^{\mathrm{a}}$ à $8^{\mathrm{a}}$ série, sendo o encaminhamento do aluno, previamente identificado em sala de aula, realizado pelo professor.

A fundamentação básica paranaense é a proposta por Joseph Renzulli (2004). No entanto, percebe-se, nesse estudo, um conhecimento eclético, isto é, a junção de ideias de diferentes teorias no discurso e na atividade prática.

$\mathrm{Na}$ metodologia, utilizou-se de entrevistas semiestruturadas com duas professoras, uma da capital e outra do interior paulista. Para a primeira, os resultados alcançados foram positivos e promissores, preocupando-se em incentivar o desenvolvimento de habilidades dos alunos, pois entende que a sala de recursos para altas habilidades ou superdotação deve ser de enriquecimento das habilidades e eventuais dificuldades devem ser atendidas em um ambiente especializado, já a outra professora observa que a parceria com os professores do ensino comum está se iniciando, ainda que muitos se preocupem mais com os problemas da sala comum. Ambas consideraram satisfatórios os resultados do seu trabalho e têm expectativas quanto às melhorias dos recursos físicos e humanos, bem como de capacitação com estudos mais aprofundados sobre a área.

Deste modo, considera-se que, apesar das dificuldades identificadas, a continuidade da proposta pode ser um importante instrumento para o enriquecimento dos alunos superdotados.

O trabalho de Fortes e Freitas (2007), denominado "PIT - Programa de Incentivo ao Talento: um relato das experiências pedagógicas realizadas com alunos com características de altas habilidades" e o de Delpretto, Fortes e Freitas (2008), "Alunos com potencial superior: uma experiência aberta ao diálogo" descrevem sobre o programa PIT. Cujo programa tem como propósito geral aprofundar e enriquecer o conteúdo curricular trabalhado na escola, desenvolvido pelo Grupo de Pesquisa Educação Especial: Interação e Inclusão Social, da Universidade Federal de Santa Maria/RS.

Esse projeto de caráter científico propóe oportunizar aos alunos, com altas habilidades ou superdotação, atividades e experiências significativas de acordo com o interesse de cada um, assim como do grupo. O programa busca, ainda, parcerias dentro da universidade, para obtenção de recursos técnicos e humanos, podendo fornecer um campo de experiências mais abrangente aos alunos e pais convidando-os a participar do programa, através de palestras e discussôes sobre a temática, de modo com que eles também possam receber orientaçóes de como ajudar seus filhos.

Desta maneira, pode-se observar que o PIT vem contribuindo de maneira significativa no desenvolvimento das pessoas com altas habilidades ou superdotação, oferecendo-lhes um ambiente enriquecedor, bem como a conscientização de pais, professores e comunidade no incentivo ao desenvolvimento de seus talentos, se 
mostrando um modelo a ser seguido por outros programas que venham a oferecer o enriquecimento curricular.

\section{Considerações finais}

O presente estudo teve como objetivo realizar uma revisão bibliográfica das produçôes científicas nacionais sobre os programas de enriquecimento escolar, com o propósito de descrever como os alunos são atendidos nesses programas, mas de modo geral, os trabalhos não descreveram sistematicamente como as atividades eram desenvolvidas, que materiais e recursos eram utilizados nas atividades, os trabalhos apontavam mesmo as suas concepçóes, o ideário e o referencial teórico seguido.

Pérez e Freitas (2011) salientam que a execução e aplicabilidade da escolarização dos alunos com altas habilidades ou superdotação ainda é insuficiente em nosso país. Esse estudo corrobora para tal afirmação, uma vez que, quando existe o enriquecimento escolar, nem sempre as atividades oferecidas se diferenciam das proporcionadas na escola regular. Evidencia a necessidade do professor em estar preparado para propiciar uma educação de boa qualidade, considerando as diferenças individuais e encorajando o desenvolvimento de talentos, competências e habilidades diversas.

Deste modo, observa-se não só a importância de se identificar o aluno com altas habilidades ou superdotação, mas de assegurar as condiçóes para o seu pleno desenvolvimento, de modo a potencializar e evitar a perda de talentos (FLEITH, 2007a). E para isso, faz-se urgente que as políticas públicas sejam efetivadas no cotidiano escolar, viabilizando tanto a formação continuada dos professores quanto propostas educacionais que assegurem o atendimento adequado a estes alunos.

No entanto, apesar das dificuldades na implementação e efetivação dos programas, podemos observar que gradualmente eles estão sendo colocados em prática e se adaptando as teorias propostas. Em vista disso, considera-se de suma importância que haja novos estudos sobre o enriquecimento escolar, de modo que essa prática se torne cada vez mais efetiva.

Nesta perspectiva, é necessário pensar e planificar ações para que a escola desenvolva no seu cotidiano práticas inclusivas. Relatar as experiências nos trabalhos supracitados é relevante no sentido de mostrar que práticas pedagógicas com alunos com altas habilidades ou superdotação são possíveis.

Contudo, incentivar e criar oportunidades para que todos os alunos desenvolvam ao máximo suas potencialidades, através de um atendimento adequado as suas necessidades, não somente aos com altas habilidades ou superdotação é de extrema relevância, ainda mais quando visamos uma escola inclusiva, para todos.

O sucesso da Educação Inclusiva, vai para além de conceder a matrícula para o aluno, ela implica mudanças significativas no ambiente escolar tanto em aspectos estruturais como em atitudinais.

Neste sentido, deve-se repensar em um novo aporte teórico e prático, que modifique as metodologias tradicionais no processo de ensino e aprendizagem, para que se atinja uma finalidade maior: uma educação democrática, em que as relaçôes sejam 
igualitárias, respeitando o potencial de todos os alunos segundo suas habilidades e interesses individuais.

\section{Referências}

ANTIPOFF, C. A. Uma Proposta Original na Educação de Bem-Dotados: ADAV-Associação Milton Campos para Desenvolvimento e Assistência de Vocaçōes de Bem Dotados em sua Primeira Década de Funcionamento: 1973-1983. 2010. 241 f. Dissertação (Mestrado em Educação) - Universidade Federal de Minas Gerais, Belo Horizonte, 2010.

CUPERTINO, C. M. B. (Org.). Um olhar para as altas habilidades: construindo caminhos. Secretaria da Educação Estudos e Normas Pedagógicas. Centro de Apoio Pedagógico Especializado. São Paulo: FDE, 2008.

DELPRETTO, B. M. L.; FORTES, C. C.; FREITAS, S. N. Alunos com potencial superior: uma experiência aberta ao diálogo. Contrapontos, Itajaí, v. 8, n. 2, p. 271-279, 2008.

FLEITH, D. S. (Org.). A construçáo de práticas educacionais para alunos com altas habilidades/superdotaçáo: volume 1: orientação a professores. Brasília: Ministério da Educação, Secretaria de Educação Especial, 2007a.

FLEITH, D. S. (Org.). A construçáo de práticas educacionais para alunos com altas habilidades/superdotação: volume 2: atividades de estimulação de alunos. Brasília: Ministério da Educação, Secretaria de Educação Especial, 2007b.

FLEITH, D. S.; ALENCAR, E. M. L. S. Desenvolvimento de talentos e altas habilidades: orientaçấo a pais e professores. Porto Alegre: Artmed, 2007.

FORTES, C. C.; FREITAS, S. N. PIT - Programa de Incentivo ao Talento: um relato das experiências pedagógicas realizadas com alunos com características de altas habilidades. Cadernos de Educaçáo, n. 29, 2007.

FREITAS, S. N. Educaçáo e Altas Habilidades/Superdotaçáo: a ousadia de rever conceitos e práticas. Santa Maria: Editora UFSM, 2006.

GUENTHER, Z. C. Centros Comunitários para desenvolvimento de talentos - O CEDET. Revista de Educaçáo Especial, Santa Maria, n. 30, 2007.

LANDAU, E. A Coragem de Ser Superdotado. São Paulo: Arte \& Ciência, 2002.

LÜDKE, M.; ANDRÉ, M. E. D. A. Pesquisa em Educação: Abordagens Qualitativas. São Paulo: EPU, 1986.

MAIA-PINTO, R. R; FLEITH, D. S. Avaliação das práticas educacionais de um programa de atendimento a alunos superdotados e talentosos. Psicologia Escolar e Educacional, Campinas, v. 8, n. 1, p. 55-66, 2004.

MARTINS, H. H. T. S. Metodologia qualitativa de pesquisa. Educaçáo e Pesquisa, São Paulo, v. 30, n. 2, p. 289-300, 2004.

METTRAU, M. B.; GONÇALVES, V. M. F. Efeitos de um programa de enriquecimento: descrição e resultados parciais. Ensaio: Avaliação e Políticas Públicas em Educação, Rio de Janeiro, v. 10, n. 36, p. 331-240, 2002.

MORI, N. N. R.; BRANDÃO, S. H. A. O atendimento em salas de recursos para alunos com altas habilidades/ superdotação: o caso do Paraná. Revista Brasileira de Educaçáo Especial, Marília, v. 15, n. 3, p. 485-498, 2009.

NOVAES, M. H. Características comportamentais do superdotado e suas implicaçóes no contexto pedagógico: a criatividade no contexto escolar. Texto digitado. In: SEESP/MEC. Adaptaçóes curriculares em ação: desenvolvendo competências para o atendimento às necessidades educacionais de alunos com altas habilidades/ superdotação. Rio de Janeiro: MEC, 2002.

PEREIRA, C. E. S.; GONÇALVES, F. C. CEDET - Um programa de sucesso na educação de dotados e talentosos Entrevista com a Prof a Dra. Zenita Cunha Guenther. Psicologia em Pesquisa, v. 1, n. 2, p. 96-106, 2007.

PÉREZ, S. G. P. B.; FREITAS, S. N. Encaminhamentos pedagógicos com alunos com Altas Habilidades/ Superdotação na Educação Básica: o cenário brasileiro. Educar em Revista, Curitiba, n. 41, p. 109-124, 2011. 
RECH, A. J. D.; FREITAS, S. N. O papel do professor junto ao aluno com Altas Habilidades. Cadernos de Educaçáo Especial. Santa Maria, UFSM, n. 25, 2005. Disponível em: <http://coralx.ufsm.br/revce/ceesp/2005/01/a5.htm>. Acesso em: 14 jun. 2013.

RENZULLI, J. S. The three-ring conception of giftedness: A developmental model for creative productivity. In: STERNBERG, R. J.; DAVIDSON, J. E. (Eds.). Conceptions of giftedness. New York: Cambridge University Press, 1986.

. O que é esta coisa chamada superdotaçáo e como a desenvolvemos? Retrospectiva de vinte e cinco anos. Revista Educaçáo, Porto Alegre, ano 27, n. 1, p. 75-134, 2004.

Three-Ring Conception of Giftedness. In: BAUM, S. M.; REIS, S. M.; \& MAXFIELD, L. R. (Eds.). Nurturing the gifts and talents of primary grade students. Mansfield Center, CT: Creative Learning Press, 1998.

RENZULLI, J. S.; REIS, S. M. The school enrichment model: how to guide for educational excellence. Mansfield Center, CT: Creative Learning Press, 1997.

VIRGOLIM, A. M. R. (Org.). Altas habilidade/superdotaçáo: encorajando potenciais. Brasília: Ministério da Educação, Secretaria de Educaçáo Especial, 2007.

WEEB, J. T.; LATIMER, D. ADHD and children who are gifted. ERIC Digest, 1993.

\section{Correspondência}

Lurian Dionizio Mendonça - Unesp, campus de Bauru. Avenida Eng. Luiz Edmundo Carrijo Coube, 14-01, CEP: 17033-360, Bauru, São Paulo - Brasil.

E-mail: luriandmendonca@gmail.com - gilafeli@gmail.com - vlmfcapellini@gmail.com

Recebido em 23 agosto 2014

Aprovado em 30 março 2015 